\title{
Corporate Social Responsibility And Sustainability Responsiveness In Business Schools: A Classification Scheme
}

Richard Peters, Xavier University of Louisiana, USA

Cary A. Caro, Xavier University of Louisiana, USA

\begin{abstract}
This paper adopts a neo-institutional perspective to help classify and explain the heterogeneity among Corporate Responsibility and Sustainability (CSRS) programs in universities. Four specific types of programs: 1) ignorer, 2) initiator, 3) imitator, and 4) innovator are identified and discussed with respect to their antecedents and potential outcomes. By considering internal and external forces simultaneously we delineate the motivation for CSRS program variety. A major perspective is that all institutions cannot prioritize CSRS education and that this decision is not based solely on internal limitations but also external realities.
\end{abstract}

Keywords: Corporate Social Responsibility and Sustainability; (CSRS) Programs in Universities

\section{INTRODUCTION}

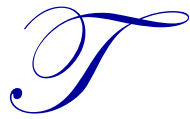

he rise in popularity of Corporate Social Responsibility and Sustainability (CSRS) throughout universities, particularly in business schools, cannot be denied (DiMeglio, 2009, 2012). Everyone seems to be talking CSRS, and with evidence that both students and corporations view it as important strategic knowledge, this popularity is far from waning.

Couple this burgeoning of CSRS in academia with the intensification of competition in higher learning (Gioia \& Corley, 2002), and predictably more programs are seeking to market themselves on their 'greening' and social consciousness. It is not surprising, therefore, that some of the most heralded business programs have some of the highest CSRS rankings (c.f. http://www.beyondgreypinstripes.org; http://www.corporateknights.com).

While everyone is talking about or carrying out CSRS activities, the majority of higher education institutions are not effectively incorporating it into their curricula and/or operational activity. A distinctive CSRS competence for a higher education program, much like a corporation, cannot be built on simple compliance or mimicry; rather, it requires an internal commitment, identification of competencies, and an encouraging external environment.

In this paper a classification scheme is created to identify and describe four types of CSRS programs. The four types, as evidenced by Figure 1, are based on the intensity of both internal and external CSRS adoption pressures faced by the program. Internal pressure originates from actors and resources within the institution. External pressure arises from factors that occupy the organization's institutional environment and affect how the business program is perceived in the eyes of its stakeholders.

The next section briefly reviews the academic literature that has focused on CSRS in higher education. A theoretical basis for classification scheme is then provided, followed by theory development and discussion of study implications. 


\section{LITERATURE REVIEW}

CSRS in education, especially in the United States, has mirrored the concept's growth in the social and corporate environment (Moon \& Orlitzky, 2011). An outgrowth of this sustained rise in prominence is the body of research that has devoted itself to discussing the role CSRS plays in university programs, especially within business schools. While these works share a common theme, heterogeneous perspectives have emerged shedding light on multiple theoretical and political motives.

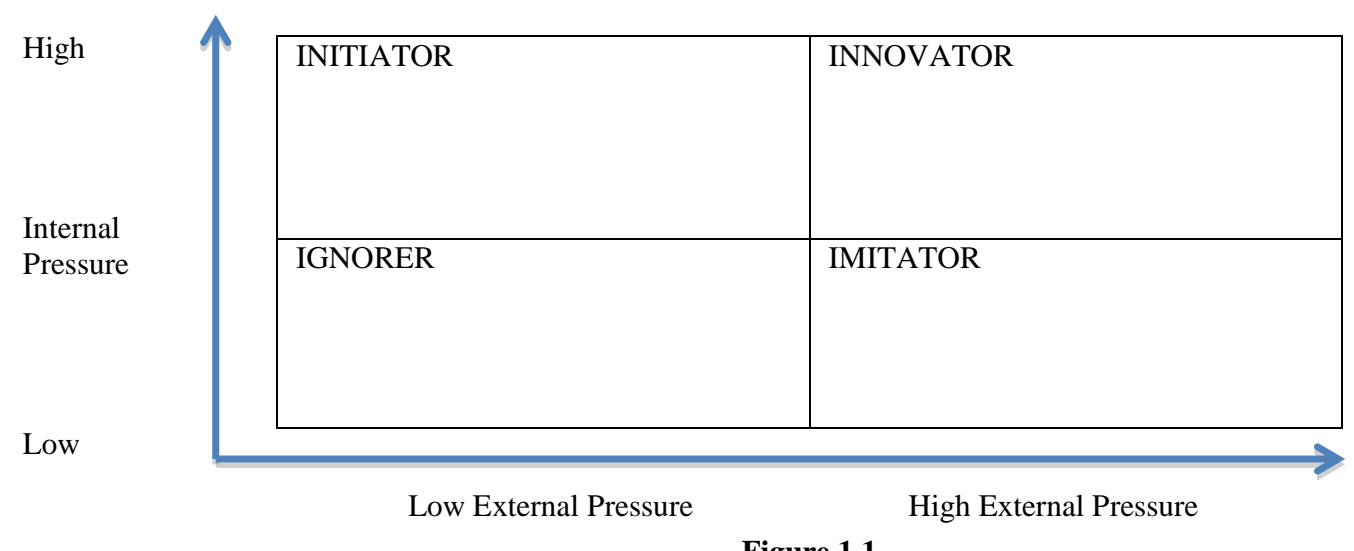

Figure 1.1

Some authors have used their research and writing to criticize a perceived 'slighting' of ethics, social responsibility, and sustainability in traditional academic programs. At the beginning of the previous decade, Gioia (2002) and Kelly (2002) argued that most U.S. MBA programs marginalized ethics training relative to the more conventional business courses, thereby prioritizing profit over purpose. This subordinate treatment of ethics and CSRS was expected to promulgate existing profit seeking, market driven ideologies, and ultimately lead to greater corruption in business management (Pfeffer \& Fong, 2002; Swanson \& Orlitzky, 2006). Since these arguments were articulated, it should be noted that the volume of criticism have decreased, and the fears of rampant corruption have generally quieted in recent years. While this could be a testament to a gained currency of CSRS in higher education (Jones Christensen, Pierce, Hartman, Hoffman, \& Carrier, 2007; Moon \& Orliztky, 2011), suspicion still exists as to whether this gain is merely image enhancement (Gioia \& Corley, 2002), or if, ironically, contemporary CSRS is just a supplement to traditional economic and strategic paradigms (Vogel, 1992).

Conversely, or perhaps in a response to this undervaluation of CSRS in academic programs, other authors have suggested alternative pedagogical approaches to teaching ethics, social responsibility, and sustainability at the university level. Giacolone and Thompson (2006) proposed that business schools needed to replace financial preoccupation with a more holistic or human-centric approach. Consequently, academics initiated and published research documenting these pedagogical experiments. Apart from established journals in the field of business ethics and CSRS giving more journal space to pedagogy, new publications have been created to expressly provide opportunities for academics to display and discuss contemporary work in CSRS education. Much like the advances alluded to previously, however, these pedagogical endeavors seem more the exception than the norm. Academics are still seemingly fighting an uphill battle to dismount the traditional approach to business from its proverbial high horse.

The unwillingness to either fully embrace CSRS, or to consider its social imperative, has been argued to be a by-product of the institutional environment of business education in the United States. Authors have noted that economic, cultural, and social forces, both historical and current, may ignore or dissuade CSRS education, and disregard CSRS's instrumental/strategic benefits in the classroom (Evans, Trevino, \& Weaver, 2006).

This neo-institutional approach to CSRS is also quite fashionable in industry study (c.f. Brammer, Jackson, \& Matten, 2012), and has been used to explain regional and national differences (Vogel, 1992; Moon \& Orlitzky, 2011). The authors suggest that variations in CSRS education can exist within one location. Similar to the 
heterogeneity found with respect to CSRS orientation and performance in the corporate America, it is proposed that all CSRS educational programs and initiatives are not created equal, and that these differences may account for performance variance across the landscape. Equally, the argument is made that these differences are motivated by the specific combination of external and internal factors that impact the program's 'strategic orientation' and, therefore, influence its ultimate character. The next section discusses this theoretical assumption and sets the stage for the classification scheme.

\section{Strategic Orientation}

Tushman and Romanelli (1985), in their discussion of organizational change and evolution, propose that strategic orientation, the value creation activities an organization employs, is determined through political, social, and economic factors. The former promote legitimacy within and outside the firm, while the latter supports the competitive goals of effectiveness and efficiency. The classification scheme relies on DiMaggio and Powel's (1993) model of institutional and competitive isomorphism to explain external forces, and borrows Tushman and Romanelli's own discussion of culture and structure to evaluate the influence of internal forces.

Both Tushman and Romanelli and DiMaggio and Powel's arguments are utilized to: 1) identify the forces present for each classification, 2) determine the goals of each classification; and, 3) delineate the governing characteristics and mechanisms likely to be found in each classification.

\section{THEORY DEVELOPMENT}

\section{Ignorer}

This classification describes a program that refrains or minimally incorporates CSRS into its content and operation. Minimal levels of both internal and external pressure which promote ethics, social responsibility, and sustainability education exist; thus, there is little likelihood that any interest in or commitment to CSRS will be apparent for this institution.

In order for external pressure to be low, the program must either exist in an institutional environment that is ambivalent or antagonistic towards CSRS, and/or be insulated from the environment by virtue of power, detachment, or independence. Neither of these scenarios is seemingly probable in an age of enhanced social awareness and academic industry competition. However, much like the extent, scope, and value of CSRS may be exaggerated in the corporate world (Vogel, 2008), the external pressure to prioritize social responsibility and sustainability may not be as widespread as some perceive. The studies and rakings that consider CSRS education often focus on top tier institutions (Jones Christensen et al., 2007), and as Moon and Orlitzky (2011) demonstrate, size of institution does influence commitment to CSRS in academia. Thus, external factors promoting CSRS education may actually be localized in few, exclusive markets.

Further, the growing trend towards 'for-profit' tertiary programs suggests that universities may be less reliant on government or social donations for their resources. This can lead to greater insulation from public demands.

Not only does an ignorer face little external pressure, but internal pressure for CSRS is also absent or minimal. This internal pressure originates from both the individuals within the program as well as resources the program has or uses. If there are no CSRS 'promoters' within the institution then it is highly unlikely, especially with little external motivation, that the program will adopt or promote CSRS behaviors. Similarly, a lack of tangible and intangible resources can lead to the absence of CSRS education.

The presence of a strong culture and the dedicated resource pool associated with existing core strengths may also hinder CSRS advocacy. Audia, Locke, and Smith (2000) term this "the paradox of success" and illustrate how past success can lead to strategic inertia and eventual failures. As Tushman and Romanelli (1985) propose, internal legitimization is a necessary step towards strategic orientation and change. Cultural acceptance in organizations is required to validate any strategic approach. Thus, if the culture, norms, and identity of the program 
are already strongly tied to something other than CSRS, those practices are far less likely to be adopted and/or prioritized. Thus programs with entrenched reputations and strengths in specific functional areas (e.g., accounting, finance, marketing) or more general trends (e.g., globalization, innovation), may find it less appealing to transfer focus away from what is familiar and onto CSRS.

\section{Initiator}

An initiator is similar to an ignorer with respect to the lack of external pressure and influence. However, internally there is some desire to legitimize CSRS in the existing program offering. As argued previously, this motivation might be people or resource driven. Regardless of the catalyst, however, the goal is pursued through the change in core culture and norms (Tushman \& Romanelli, 1985).

As Chandler (1962) posits, structure follows strategy; therefore, advocates of CSRS in initiator type programs first seek to the change the mindset and sense-making of actors within the institution before changing the operational and structural processes. These advocates are often personally committed to the tenets of CSRS and adopt the role of 'discipline champion', even at great professional cost (Orr, 2000). Their task is to 'sell' their uncertain, suspicious, and sometimes defiant audience and leaders on the benefit of CSRS education (Dresner, 2002).

Suspicions and defiance towards CSRS arise because of the inherent ambiguity of the construct, its perceived lack of scientific rigor, issues of measurability, and the presence or absence of finite or slack resources (Velazquez, Munguia, \& Sanchez, 2005; Cotton, Bailey, Warren, \& Bissell, 2009).

Considering that advocates question the status quo, they are most likely to be either newer members of the institution or members with numerous weak ties to external people and organizations (Granovetter, 1973). Boeker (1997), for example, finds evidence that CEO succession in organizations leads to greater strategic change. Complementarily, Alexiev, Jansen, Van den Bosch, and Volberda (2010) propose that organizational heads that are open to external advice will stimulate organizational innovation. Newness and/or openness, therefore, reduce the likelihood of fear or socialization preempting change advocacy and increases the willingness to champion an unpopular or unconsidered discipline such as CSRS.

Once the program buys into the ideals and merit of CSRS education, the lack of external factors supporting this change can pose a significant obstacle to its actual implementation. While those internal to the organization may find merit to this form of education, consumers and other stakeholders may not be convinced; thus, the program may find itself with a potential strength that has no external opportunity to exploit. Similar scenarios exist in the corporate world where firms complain that they possess an internal desire to increase their CSRS activity, but they are tempered by stakeholder unwillingness to value this behavior.

\section{Imitator}

The third CSRS classification is where it is suggested most programs reside. Despite the lack of internal catalysts, the external pressure, whether real or perceived, contributes to the program's 'positive response' to CSRS.

The political/social goal when responding to external forces in Tushman and Romanelli's model is to gain external legitimization. Suchman (1995, p. 574) defines legitimacy as a "generalized perception or assumption that the actions of an entity are desirable, proper, or appropriate within some socially constructed system of norms, values, beliefs and definitions." Essentially, organizations, and their behavior, are justified when they 'play' by the rules that their external environment stipulates. This concept of legitimacy is the central theme of DiMaggio and Powell's (1983) work on isomorphism, in which they argue that organizations will adopt or conform to similar structural patterns in order to be perceived as legitimate by their stakeholders. Naturally, the varied forms of institutional pressures create variations of isomorphism.

Coercive isomorphism is largely cultivated and realized by pressures exerted on an organization from those they are most dependent upon. For a business program at a traditional university, these mandates, expectations, or 
requirements can come from governments, granting agencies, accreditation bodies, and alumni. Based on the resource dependency perspective, organizations respond to the needs and demands of stakeholders that provide access to most significant requisites for organizational wellbeing (Pfeffer \& Salancik, 1978). Suchman (1995) labels this as pragmatic legitimacy, and notes that in its pursuit, organizations are seeking to convince regulatory and asset granting entities of their social acceptability. This type of isomorphism is motivated more by fear of punishment rather than opportunity for reward; thus, the program is likely to see CSRS adoption as little more than a 'necessary evil'. This will inevitably lead to minimal resource allocation or even simple 'window dressing' (Meyer \& Rowan, 1977).

Mimetic isomorphism stems from high levels of uncertainty surrounding either what types of behavior is required by society or a lack of understanding of how this behavior can be achieved. As previous authors have proposed (Velazquez, Munguia, \& Sanchez, 2005; Cotton, Bailey, Warren, \& Bissell, 2009), these two areas of uncertainty are systemic to, and pervasive in, CSRS education. Therefore, it is expected that many programs will imitate peers, with respect to CSRS agendas, to merely keep current with other peer institutions or organizations.

There is nothing inherently wrong with imitation; in fact, benchmarking can be a useful planning tool. One should recall, however, that imitator type programs have little or no internal CSRS pressure (culture, processes, people or resources); thus, organizational mimicry is often executed either inappropriately or ineffectively. The former occurs because the institution adopts practices and content that is too general or nuanced for their audience. Moon and Ortlitzky (2011) show that CSRS programs vary across geographic regions, and a similar argument can be made for intra-regional differences. Therefore wholesale adoption, with little customization may lead to problematic issues. Ineffectiveness, accompanies the absence of resources and cultural support within the organization (Velazquez et al., 2005). Not only are these programs unsure about what to do, but they also lack the tools to effectively implement the processes and projects of their better-resourced peers. Further, since these programs are more concerned with the appearance of legitimacy rather than the production of results, they are unlikely to acquire or cultivate the resources needed to fully benefit from CSRS. Their mimicry, therefore, leads to ultimate inferiority and further marginalization of CSRS in the overall educational program.

Normative isomorphism, similar to coercive and mimetic, originates in the external institutional environment. It is facilitated through the professional linkages the organization forms via its members' educational history and networks, as well as its own professional ties (DiMaggio \& Powell, 1983). As more academics become assimilated, educated, and experienced in CSRS, it is expected that these socialization activities will result in greater normative pressures for social responsibility and sustainability in business programs. Also, programs themselves, through partnerships and academic memberships, can learn more about CSRS, thus they are more likely to incorporate it, in some fashion, in its offering.

Akin to mimetic isomorphism, however, the institution is ill prepared to leverage the advantages of the discipline. Despite having more people aware of the topic, the organization may still be lacking important cultural and tangible resources necessary for its successful implementation.

The underlying and common thread among all three types of isomorphism is that they are largely forced upon the institution either through coercion or cognition. Therefore, the program is essentially a passive participation, with little or no internal interest or motivation. The potential for any strategic benefit, much less the derivation of a competitive advantage, is substantially diminished. In these instances, therefore, the best possible outcome is that the discipline acts as a 'silent token partner', promoting legitimacy but doing little else.

\section{Innovator}

The fourth classification results from the infusion of high external and internal pressure. With respect to external factors, the program, much like the imitator, is expected to seek legitimization from stakeholders. Innovators, however, are expected to progress beyond social legitimization and respond to what DiMaggio and Powell (1983) term as competitive isomorphism. Unlike institutional isomorphism (coercive, mimetic, and normative), competitive isomorphism focuses on operational effectiveness and efficiency, and is more marketoriented in its mechanisms and goals (Tushman \& Romanelli, 1985). 
A major distinction between institutional and competitive isomorphism is that in the latter, the organization is acting voluntarily and proactively to distinguish itself from its competitors, primarily in the eyes of its consumer. Essentially, the organization seeks, through behavior and communication, to carve its niche of uniqueness in the competitive landscape.

The goal, as previously mentioned, is not simply social acceptance but operational effectiveness. This effectiveness is ultimately contingent on the extent of competitive isomorphism, which is only present if stakeholders, especially consumers, appreciably value CSRS education. It is insufficient for them to be ambivalent or even accommodating; they must truly be desirous of it. As noted earlier, this intensity of CSRS valuation and desire may be limited to only a handful of markets. This localization effect is also evident in the corporate world. The inconsistency of results related to the financial benefit of CSRS to business corporations (Orlitzky, Schmidt, \& Rynes, 2003) indicates that the strategic advantage of social responsibility and sustainability may only be fully realized in markets where consumers are both willing and able to pay for this virtue (Oberseder, Schlegelmilch, \& Gruber, 2011).

Internally, innovators are also distinct from other classifications. Their culture is expected to embrace CSRS is a very explicit and committed manner (Moon \& Orlitzky, 2011). Values and norms associated with the discipline are likely to be expressed in vision and mission statements. Moreover, endeavors and options associated with social responsibility and sustainability are expected to be both accepted and prioritized.

Beyond the polity, the 'economic' goal, as defined by Tushman and Romanelli's model is operational efficiency. The program seeks accomplishment of this goal through structural changes, process implementation, and incentive schemes. Innovators are likely to house CSRS centers or create explicit faculty and staff roles dedicated to CSRS. Further these institutions will likely offer complete degrees or certification in ethics, social responsibility, and/or sustainability curriculum. Faculty will also be rewarded for efforts and performance related to the discipline, similar to traditional functional areas.

The major point of distinction between imitators and innovators is the strategic emphasis placed on their CSRS implementation. In a discussion of corporate philanthropy, Porter and Kramer (2002) posit that corporate giving is strategic when it effectively marries the economic goals of the organization with the social needs of stakeholders. Strategic philanthropy is selective and focused on leveraging the firm's strengths to best serve society's needs. Ricks and Peters (2013) expand on this premise and argue that strategic philanthropy must not only be selective, but measurable in terms of outcomes, such that the firm can evaluate whether it's giving definitively addresses both sets of needs (economic and social).

Applying this philosophy to CSRS education, it is argued that innovators apply a strategic lens to their program implementation. They are the least likely to imitate others and most likely to create and customize offers specific to their target audience. These then become the best practices of the industry and lead to the reputational and competitive advantages CSRS innovators enjoy.

\section{CONCLUSION}

Despite the strides made in CSRS education, many academics professionally and personally, still feel like Sisyphus when trying to advocate for, and implement, the discipline into mainstream business education. It seems as if it always requires more validation and evidence to be recognized and represented as an integral part of higher education.

Others have identified key institutional obstacles and impediments to CSRS's acceptance and growth, but here, through an institutional perspective, it is argued that a combination of external forces and internal factors, are the ultimate determinants of CSRS adoption and deployment in the classroom and on the campus.

The classification scheme demonstrates that heterogeneity among programs is possible and probable, even in a developed CSRS society like the United States. As has been mentioned and argued, institutional forces can and often do vary within regions, nations, and even industries. Thus treating CSRS education as a dichotomy of either 
having it or not having it is excessively simplistic and misleading. Further, categorizing CSRS education programs as either good or bad is also prohibitive and unfortunately judgmental.

This article has taken great pains to appear neither critical nor prescriptive with respect to CSRS delivery and prioritization. Instead the focus here is on evaluation and explanation: first to demonstrate why CSRS heterogeneity exists among programs, and then to identify the consequences and implications of such variance. As such, programs are not morally instructed or implored to adopt an innovator approach, although this may be viewed as the optimal type (both morally and strategically). In fact, it may be strategically feasible, based on external and internal factors, for some institutions to be imitators. If the program does not have core strengths in CSRS and if the environment requires only 'acceptable' CSRS incorporation, then it would seem strategically prudent for the program to meet its external obligations, but do no more. In fact, many programs cannot become innovators, since the market for CSRS education, although expanding, may be more prohibitive than once believed.

It should thus be clear from this discourse that is both naïve and irresponsible to expect/and or demand that all programs virtuously promote CSRS education. Further to advocate internal changes without consideration for institutional determinants is to ignore the competitive and complex stakeholder environment most programs occupy. Internal transformation is most often preceded by external stimuli. It might be prudent for researchers in the field to shift our away from the schools and towards the institutions that shape and influence their world. Thus, a sustainable inside begins with a supportive outside.

\section{AUTHOR INFORMATION}

Richard Peters, Ph.D., Xavier University of Louisiana, USA. Dr. Richard Peters is an Assistant Professor of Management at Xavier University of Louisiana. He currently teaches at the Undergraduate level in the Division of Business. His research interests are in corporate social responsibility and sustainability (CSRS) and international CSRS pedagogy, with a recent emphasis on emerging markets. He has published articles in the International Journal of Management and Enterprise Development and Journal of Management and Organization (forthcoming) and has presented at numerous national and regional conferences. E-mail: rpeters1@xula.edu

Cary A. Caro, Ph.D., Xavier University of Louisiana, USA. Dr. Cary Caro is an Assistant Professor of Management at Xavier University of Louisiana, where he teaches at the undergraduate level in the Division of Business. His research interests include sports economics, human resource development, sustainability, and corporate social behavior. He has published in the International Journal of Sports Science and Coaching and the American Journal of Criminal Justice. He currently serves at Managing Editor for the American Journal of Business Education. E-mail: ccaro@xula.edu (Corresponding author)

\section{REFERENCES}

1. Alexiev, A. S., Jansen, J. J. P., Van Den Bosch, F. A. J., \& Volberda, H. W. (2010). Top management team advice seeking and exploratory innovation: The moderating role of TMT heterogeneity. Journal of Management Studies, 47(7), 1343-1364.

2. Audia, P. G., Locke, E. A., \& Smith, K. A. (2000).The paradox of success: An archival and a laboratory study of strategic persistence following radical environmental change. Academy of Management Journal, 43(5), 837-853.

3. Boeker, W. (1997). Strategic change: The influence of managerial characteristics and organizational growth. Academy of Management Journal, 40(1), 152-170.

4. Brammer, S., Jackson, G., \& Matten, D. (2012) Corporate social responsibility and institutional theory: New perspectives on corporate governance. Socio-Economic Review, 10(1), 3-28.

5. Chandler, A. D. (1962). Strategy and structure: Chapters in the history of the American industrial enterprise. Cambridge, MA: MIT Press.

6. Cotton, D. R. E., Bailey, I., Warren, M. F., \& Bissell, S. (2009). Revolutions and second-best solutions: Education for sustainable development in higher education. Studies in Higher Education, 34, 719-733.

7. Di Meglio, F. (2009). MBA programs go green. Businesweek, January 19.

8. Di Meglio, F. (2012). Going green: MBA sustainability programs. Businessweek. April 17. 
9. DiMaggio, P. J., \& Powell, W. (1983). The iron cage revisited: institutional isomorphism and collective rationality in organizational field. American Sociological Review, 48, 147-60.

10. Dresner, S. (2002). The principles of sustainability. London: Earthscan Publications Limited.

11. Evans, J. M., Trevino, L. K., \& Weaver, G. R. (2006). Who's in the ethics driver's seat? Factors influencing ethics in the MBA curriculum. Academy of Management Learning and Education, 5(3), 278293.

12. Giacalone, R. A., \& Thompson, K. R. (2006). Business ethics and social responsibility education: Shifting the worldviews. Academy of Management Learning and Education, 5(3), 266-277.

13. Gioia, D. A., \& Corley, K. G. (2002). Being good vs. looking good: Business school rankings and the Circean transformation from substance to image. Academy of Management Learning and Education, 1(1), 107-120.

14. Gioia, D. A. (2002). Business education's role in the crisis of corporate confidence. Academy of Management Executive, 16(3), 142-145.

15. Granovetter, M. S. (1973). The strength of weak ties. American Journal of Sociology, 78(6), 1360-1380.

16. Jones Christensen, L., Peirce, E., Hartman, L. P., Hoffman, W. M., \& Carrier, J. (2007). Ethics, CSR, and sustainability education in the Financial Times top 50 global business schools: Baseline data and future research directions. Journal of Business Ethics, 73(4), 347-368.

17. Kelly, M. (2002). It's a heckuva time to be dropping business ethics programs. Business Ethics, 16(5-6), 17-18.

18. Meyer, J. W., \& Rowan, B. (1977). Institutional organizations: Formal structure as myth and ceremony. American Journal of Sociology, 83(2), 340-363.

19. Moon, J., \& Orlitzky, M. (2011). CSR and sustainability education: A trans-atlantic comparison. Journal of Management and Organization, 17(5), 583-603.

20. Orlitzky, M., Schmidt, F. L., \&. Rynes, S. L. (2003). Corporate social and financial performance: A metaanalysis. Organization Studies, 24(3), 403-441.

21. Orr, D. (2000). Transformation of academic planning for environmental education in the $21^{\text {st }}$ century. In W. Leal Filho (Ed.), Sustainability and university life (p. 221). Peter Lang, Frankfurt.

22. Pfeffer, J., \& Fong, C. T. (2002). The end of business schools? Less success than meets the eye. Academy of Management Learning and Education, 1(1), 78-95.

23. Pfeffer, J., \& Salancik, G. R. (1978). The external control of organizations: A resource dependence approach. New York: Harper and Row.

24. Porter, M. E., \& Kramer, M. R. (2002). The competitive advantage of corporate philanthropy. Harvard Business Review, December, 57-68.

25. Ricks, J., \& Peters, R. (2013). Motives, and models, of philanthropy: Towards a typology of strategic corporate philanthropy. Business and Society Review, 18(3). 413-436.

26. Suchman, M. C. (1995). Managing legitimacy: Strategic and institutional approaches. Academy of Management Review, 20(3), 571-610.

27. Swanson, D. L., \& Orlitzky, M. (2006). Executive preference for compensation structure and normative myopia: A business and society research project. In R. W. Kolb (Ed.), The ethics of executive compensation (pp. 13-31). Malden, MA: Blackwell.

28. Tushman, M., \& Romanelli, E. (1985). Organizational evolution: A metamorphosis model of convergence and reorientation. In L. L. Cummings \& B. M. Staw (Eds.), Research in organizational behavior (Vol 7; pp. 171-222). Greenwich, CT: JAI Press.

29. Velazquez, L., Munguia, N., \& Sanchez, M. (2005). Deterring sustainability in higher education institutions: An appraisal of the factors which influence sustainability in higher education institutions. International Journal of Sustainability in Higher Education, 6(4), 383-391.

30. Vogel, D. (1992). The globalization of business ethics: Why America remains distinctive. California Management Review, 35, 30-49.

31. Vogel, D. (2008). CSR doesn't pay. Forbes. April 16. 